\title{
Routledge Performance Archive
}

The Routledge Performance Archive, produced in partnership with Digital Theatre, provides unique access to an unprecedented range of audio-visual material from past and present practitioners of performance.

The Archive includes interviews, master-classes, unique footage, excerpted and full-length contemporary productions and documentaries, including Avner Eisenberg's A Discourse on Clowning, Goat Island's The Lastmaker, selected sound art fragments from Guillermo Gomez-Pena, Jos Houben's The Art of Laughter, Rena Mireck 's The Dream, Odin Teatret's Ascent to the Sea, an introduction to Kathakali Dance-Drama from Phillip Zarrilli, and an actor training workshop from David Zinder.

\section{What you can do with the Archive}

This ground-breaking online collection delivers essential resources direct to the classroom, lecture theatre and library. The Archive provides a single portal which can be searched easily by subject, practitioner or keyword, including unique and unprecedented footage perfect for teaching as well as research purposes. Subscribe to the Archive to:

- Watch exclusive videos from practitioners' own archives

- Listen to unique audio material

- Read first-hand accounts, authoritative definitions and contextualising commentary

- Make connections across many decades of theatre-making

- Construct maps and genealogies

- Explore themes and ideas about performance practice

- Create pathways

- Discover practitioners, methods, styles of work

- Think about performance practice and documentation

- Identify origins and relevance

- Look at how practice shapes performance

- Find evidence to support research

- Select ideas and images to illustrate them

- Identify influences and approaches

- Investigate gaps and silences

- Compare cultures and eras

- Draw timelines and reveal traces.

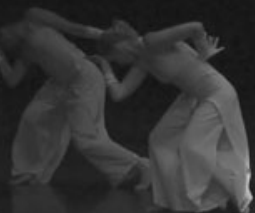

密 Routledge

\section{Regular Content Updates}

As a developing resource the Routledge Performance Archive is constantly growing. Recent additions include exclusive content from the Victoria \& Albert Museum's National Video Archive of Performance Recordings. Keep visiting the site to find out more about our regular content updates.

\section{Request a Free Trial}

The simplest way to learn more about the Routledge Performance Archive is to experience it for yourself.

Arrange your no obligation free trial at: www.routledgeperformancearchive.com

To find out more about subscriptions please contact us:

sales.rpa@routledge.com

www.routledgeperformancearchive.com 


\section{CAMBRIDGE}

\section{New Theatre Titles from Cambridge University Press!}

Shakespeare Beyond Doubt Evidence, Argument, Controversy

Edited by PAUL EDMONDSON and STANLey Wells

S85.00: Hb: 978-1-107-01759-7: $304 \mathrm{pp}$. S29.99: Pb: 978-1-107-60328-8

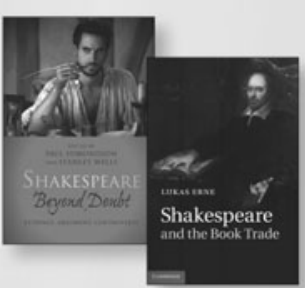

Shakespeare

and the Book Trade

LUKAS ERNE

S44.99: Hb: 978-0-521-76566-4: $316 \mathrm{pp}$.

Second Edition!

Shakespeare as

Literary Dramatist

LUKAS ERNE

S85.00: Hb: 978-1-107-02965-1: $320 \mathrm{pp}$. S29.99: Pb: 978-1-107-68506-2

Second Edition!

The Tempest

Edited by David LindLeY

The New Cambridge Shakespeare

S45.00: Hb: 978-1-107-02152-5: $300 \mathrm{pp}$. S16.99: Pb: 978-1-107-61957-9

Samuel Beckett's Library

Dirk Van Hulle

and MARK NIXON

S90.00: Hb: 978-1-107-00126-8: 342 pp.

\section{Environmental}

Degradation

in Jacobean Drama

BRUCE BOEHRER

S90.00: Hb: 978-1-107-02315-4: 221 pp.

The Cambridge

Introduction to

Theatre Directing

Christopher Innes

and Maria Shevtsova

Cambridge Introductions to Literature

575.00: Hb: 978-0-521-84449-9: 304 pp.

S24.99: Pb: 978-0-521-60622-6

The Cambridge

Introduction to

Tom Stoppard

William Demastes

Cambridge Introductions to Literature

580.00: Hb: 978-1-107-02195-2: 177 pp.

S27.99: Pb: 978-1-107-60612-8

\section{The Cambridge \\ Companion to \\ Theatre History}

Edited by David WILES and Christine Dymkowski Cambridge Companions to Literature S90.00: Hb: 978-0.521-76636-4: $336 \mathrm{pp}$. S29.99: Pb: 978-0.521-14983.9

Late Shakespeare, 1608-1613

Edited by

ANDREw J. Power

and RORY LOUGHNANE

599.00: Hb: 978-1-107-01619-4: 355 pp.
Early Modern Playhouse

Manuscripts and the Editing of Shakespeare

Paul Werstine

S99.00: Hb: 978-1-107-02042-9: 443 pp.

\section{Medieval Shakespeare}

Pasts and Presents

Edited by RUTH MORSE, Helen Cooper, and Peter Holland

S99.00: Hb: 978-1-107-01627-9: 278 pp.

\section{Samuel Beckett in Context}

Edited by AnTHONy UhLMANN Literature in Context

599.00: Hb: 978-1-107-01703-0: 400 pp.

Scenes and Machines on the English Stage during the Renaissance A Classical Revival

Lilly B. CAMPBell

S31.99: Pb: 978-1-107-62084-1:332 pp.

The Performance of Nationalism

India, Pakistan, and the Memory of Partition

Jisha Menon

Cambridge Studies in Modern Theatre S99.00: Hb: 978-1-107-00010-0: 272 pp.

The Shakespearean Stage Space

MARIKO ICHIKAWA

S95.00: $\mathrm{Hb}$ : 978-1-107-02035-1: $236 \mathrm{pp}$

Prices subject to change. 


\title{
The American Society for Theatre Research
}

The American Society for Theatre Research (ASTR) is a U.S.-based professional organization that fosters scholarship on worldwide theatre and performance, both historical and contemporary. ASTR was founded in 1956 to encourage theatre scholarship in the United States and to provide a link to similar research-oriented organizations, such as the International Federation for Theatre Research/La Fédération Internationale pour la Recherche Théatrale (IFTR/FIRT). ASTR was incorporated under the laws of the state of New Jersey as a nonprofit corporation in 1967, and is the only theatre organization in the United States formally affiliated with both the American Council of Learned Societies and with the IFTR/FIRT. The ASTR Annual Meeting occurs in the fall of each year.

Theatre Survey, the official journal of ASTR, is published three times a year, in January, May, and September, and is one of the benefits of membership in the Society. ASTR annual dues for North Americans are $\$ 115.00$ for individual members, $\$ 40.00$ for retired members, $\$ 35.00$ for students. Foreign members pay an additional $\$ 7.50$ in each of the above categories. Inquiries about ASTR, including membership, should be directed to:

\section{Nancy Erickson \\ NEricksn@aol.com}

The American Society for Theatre Research

P.O. Box 1798

Boulder, CO 80306-1798

Telephone: (888) 530-1838

Fax: (303) 530-1839

http://www.astr.org/

\section{Officers And Executive Committee of ASTR}

\author{
Heather Nathans (President, 2012-2015) \\ Patrick Anderson (Vice-President, 2012-2015) \\ Marla Carlson (Secretary, 2011-2014) \\ Cindy Brizzell-Bates (Treasurer, 2011-2014) \\ Executive Committee members \\ Robin Bernstein (2012-2015) \\ Gay Gibson Cima (2010-2013) \\ Soyica Colbert (2011-2014) \\ Elinor Fuchs (2010-2013) \\ Brian Herrera (2010-2013) \\ Kellyn Johnson (Graduate Student Representative, 2012-2013) \\ Suk-Young Kim (2011-2014) \\ Kirsten Pullen (2011-2014) \\ Jill Stevenson (2012-2015) \\ Shane Vogel (2012-2015) \\ E.J. Westlake (2012-2015) \\ Leigh Woods (2011-2014)
}




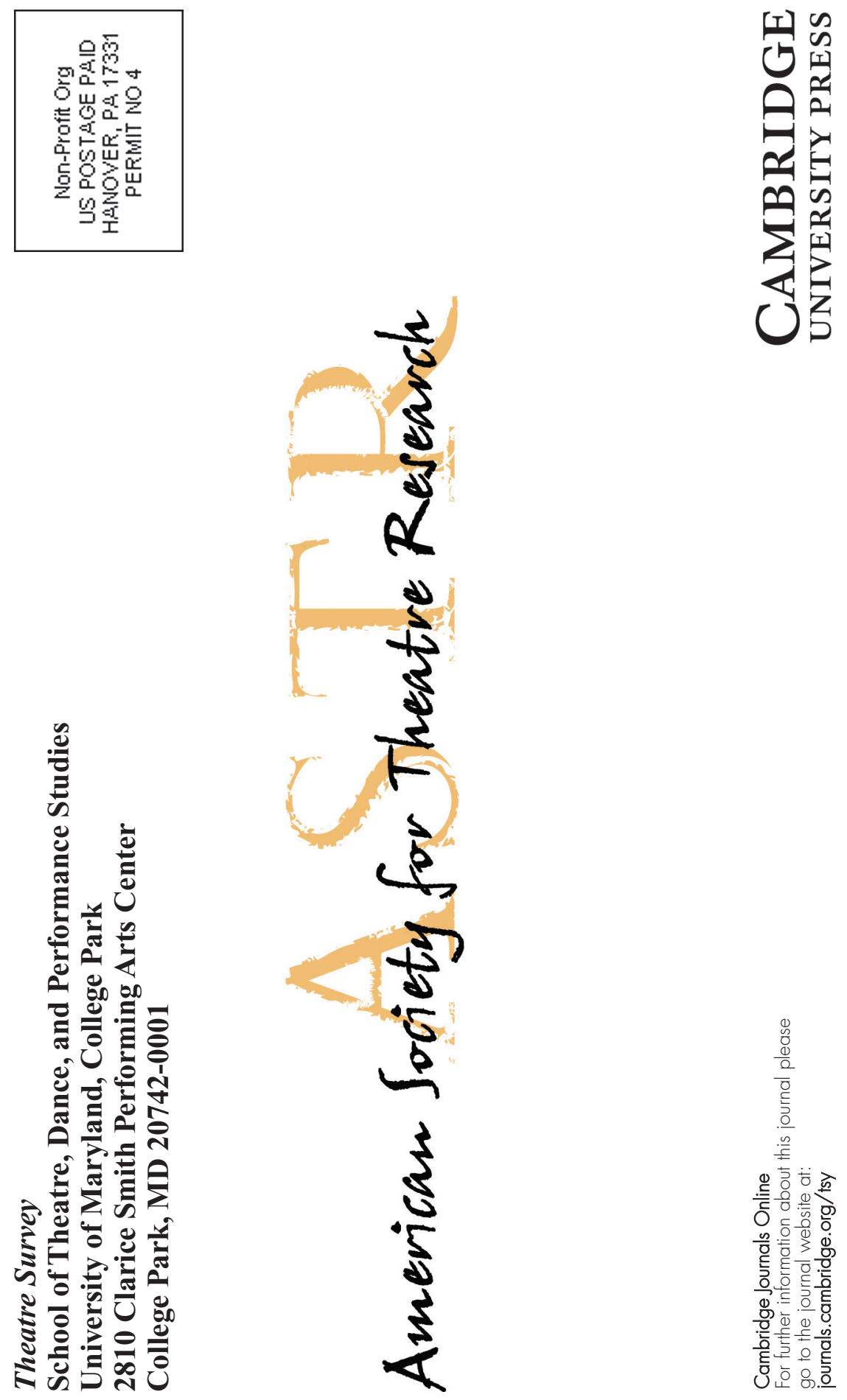

